\title{
Creep Characteristics of Different Saturated States of Red Sandstone after Freeze-Thaw Cycles
}

\author{
Yongxin Che $(\mathbb{D}$, Yongjun Song $(\mathbb{D}$, Jianxi Ren, Jiaxing Chen, Xixi Guo, Hao Tan, \\ and Mengling Hu \\ College of Architecture and Civil Engineering, Xi'an University of Science and Technology, Xi'an 710054, China \\ Correspondence should be addressed to Yongjun Song; songyj79@163.com
}

Received 3 January 2021; Revised 8 June 2021; Accepted 21 August 2021; Published 10 September 2021

Academic Editor: Kai Yao

Copyright (c) 2021 Yongxin Che et al. This is an open access article distributed under the Creative Commons Attribution License, which permits unrestricted use, distribution, and reproduction in any medium, provided the original work is properly cited.

To investigate the creep mechanical characteristics of rocks in different saturated states after freeze-thaw cycles, samples with different saturations $(30 \%, 50 \%, 70 \%, 90 \%$, and 100\%) were selected for nuclear magnetic resonance (NMR), scanning electron microscopy (SEM), and uniaxial compression creep tests. The internal microscopic damage of the rock sample and mechanical characteristics under long-term loading are analyzed after the action of freeze-thaw cycles. The test results show that, as the saturation increases, the T2 spectrum distribution shifts to the right. The spectrum area gradually increases as the porosity increases. The critical saturation of freeze-thaw damage occurs when the saturation increases from $70 \%$ to $90 \%$. It can be seen from the SEM image that the number of pores inside the rock samples gradually increases with increases in saturation, leading to the appearance of cracks. Under long-term loading, the saturation has a significant influence on the time-efficiency characteristics of sandstone freeze-thaw. As the saturation increases, the creep deformation gradually increases. After reaching $70 \%$, the axial creep strain increases significantly. The rate of creep is accelerated, the creep failure stress is reduced, and the creep time under the last level of stress is significantly increased. A modified viscous-plastic body is connected in series to the basic Burgers model, the freeze-thaw-damage viscous element is introduced, and the creep parameters are fitted using test data. The results will provide a reference for long-term antifreeze design for rock engineering in cold areas.

\section{Introduction}

Rock masses in cold regions are subjected to the thermal action of seasonal changes and day-night cycles for long periods of time, leading to severe damage and deterioration. Geotechnical engineering in mines and tunnels in the cold regions of western China operate in freeze-thaw environments, with significant loads and surrounding rock pressure for extended periods of time. Rock creep under long-term loading significantly affects the long-term stability of rock masses. If the long-term effects of freeze-thaw and load are not considered at the same time, it will bring safety hazards to engineering construction in cold areas. Therefore, studying the creep characteristics of rock-mass engineering under the action of freeze-thaw cycles and investigating the time-efficiency characteristics play an important role in ensuring the long-term stability of rock-mass engineering in cold regions.
In recent years, Li et al. [1] investigated the influence of the number of freeze-thaw cycles and graded loads on creep and established a nonlinear creep constitutive model of freeze-thaw sandstone. Zhou et al. [2] conducted a triaxial unloading creep test on sandstone; the results showed that both the unloading process and the freeze-thaw cycle can improve the creep deformation of the rock sample, where radial deformation is more sensitive. Chen et al. [3] conducted triaxial creep tests on quartz sandstone after different freeze-thaw cycles. The research showed that the microdamage caused by freezing and thawing can lead to strong creep characteristics; the creep mechanical parameters are obviously changed with the increase in freeze-thaw cycles. Yang et al. [4] carried out triaxial creep tests and microscopic tests under the freeze-thaw cycle and systematically analyzed the operating mechanism of the effects of freezing and thawing on the creep characteristics of gneiss. Liu et al. [5] carried out a triaxial creep test on carbon shale under freeze-thaw 
action and determined the nonlinear characteristics of creep damage. It was concluded that, under the combined action of freeze-thaw and creep, the freeze-thaw action would accumulate rock damage and accelerate creep failure. Zhang et al. [6] proposed the freeze-thaw rock damage viscous element and constructed a constitutive model for granite freeze-thaw shear creep. Zhou et al. [7, 8] carried out mechanical and micro-microscopic tests on prefabricated fractured sandstone after freezing and thawing; the interaction mechanism of moisture inside the defective rock mass and the evolution of the fatigue damage zone of the rock mass have been fully studied under the action of freezing and thawing cycles.

It can be seen from the above research that the freezethaw cycle has a significant influence on the long-term mechanical properties of rocks; however, most current creep research is only carried out in the fully saturated state. Owing to the several changes in geology, geography, climate, and hydrology over the years, the water content of rock masses differs significantly.

McGreevy and Whalley [9] believed that the initial water content of a rock mass determines the degree of frost-heave damage, and the water content will fluctuate with the number of freeze-thaw cycles, freezing duration, and seasonal changes. Liu et al. [10] found that the freeze-thaw damage of rock masses is dependent on the initial saturation, which has an important influence on the frost-heave force. Only the rock masses that exceed the critical value of saturation will lead to effective freeze-thaw damage [11, 12]. Chen et al. [13] carried out uniaxial compression, longitudinal wave velocity, and porosity-measurement tests on tuffs with different initial saturations after the freeze-thaw process, and the results showed that a saturation of $70 \%$ is the critical value for effective freeze-thaw damage. The level of saturation has a significant influence on the long-term mechanical properties of the rock mass. Al-Omari et al. [14] found that the critical saturation is the main factor that dictates the freeze-thaw failure of limestone in the Chambord Castle in France. With the goal of understanding the time-efficiency deterioration of rocks at different saturations, Zhang et al. [15] proposed an elastic-viscous-plastic model based on a stress function of the influence of freeze-thaw cycles on the characteristics of saturated rocks and the rheological theory. Yang et al. [16] conducted a triaxial creep test for soft rock under water-bearing conditions, where the change law of creep deformation was analyzed. Liu et al. [17] tested slabs under different water-bearing conditions using the rock creep test and established the FLAC3D creep constitutive secondary development model, which considers the effect of water-bearing degradation. Zhang et al. [18] took the auxiliary tunnel of Jinping II Hydropower Station as an example to study the time-dependent deformation of rock tunnels and established a novel four-element fractional viscoplastic (FVP) model based on the test results. Wang et al. $[19,20]$ carried out uniaxial long-period cyclic load creep tests on rock salt specimens under different maximum cyclic stresses and cyclic periods and analyzed the law of creep stage, creep rate, and elastic modulus with stress and number of cycles.
TABLE 1: Composition of rock samples.

\begin{tabular}{ccccc}
\hline Quartz & Plagioclase & Calcite & $\begin{array}{c}\text { Potash } \\
\text { feldspar }\end{array}$ & $\begin{array}{c}\text { Clay minerals and other } \\
\text { constituents }\end{array}$ \\
\hline $53.0 \%$ & $17.9 \%$ & $8.9 \%$ & $9.9 \%$ & $10.3 \%$ \\
\hline
\end{tabular}

The above studies have laid the foundation for understanding rock creep characteristics and the influence of saturation on rock instantaneous mechanical properties under the effect of freeze-thaw cycles. However, there are few reports on the long-term mechanical properties of rocks with different saturation levels under freeze-thaw cycles. This paper conducts NMR, scanning electron microscopy, and uniaxial compression creep tests on red sandstone in different states of saturation after freeze-thaw cycles and analyzes the microscopic and creep damage mechanisms. Based on the Burgers model, a freeze-thaw damage creep model-considering the effect of saturation-is established. Further, the experimental value and fitted theoretical values are compared, finally obtaining the creep parameters. The results of this research will provide a reference and basis for long-term antifreeze design for rock engineering in cold areas.

\section{Materials and Methods}

2.1. Rock Samples. The rock samples were taken from a tunnel slope in a cold region in western China. Owing to the differences in water content of slopes at different heights, the stability of the slope will gradually weaken under the action of freeze-thaw cycles and long-term loads [21]. The D8Venture X-ray single crystal diffractometer was used to analyze the mineral composition of the rock samples. The mineral composition is shown in Table 1. The internal particles of the rock sample were pore-type cemented, which is a moderately swollen weakly cemented soft rock.

In accordance with the test regulations of the International Society of Rock Mechanics, the rock sample was processed into a standard cylinder with a diameter of $50 \mathrm{~mm}$ and a height of $100 \mathrm{~mm}$. A rock sample with good integrity was selected and baked in an oven at $105^{\circ} \mathrm{C}$ for 24 hours; the primary wave velocity and dry density of rock samples were measured after cooling. The variation range of primary wave velocity and dry density states that $(1832<v<1865 \mathrm{~m} / \mathrm{s})$ and $\left(2.30<\rho<2.32 \mathrm{~g} / \mathrm{cm}^{3}\right)$, respectively. Three groups were subjected to nuclear magnetic resonance (NMR), conventional uniaxial compression tests, and uniaxial compression creep tests, totaling 15 rock samples, as shown in Figure 1(c). The average values of the initial basic physical parameters for the rock samples are shown in Table 2.

\subsection{Test Plans}

2.2.1. Preparation of Rock Samples with Different Saturated States. All rock samples were subjected to forced saturation for 24 hours using a vacuum saturating machine to obtain completely saturated rock samples. The rock sample was subsequently naturally air-dried, and its quality was monitored at regular intervals until the corresponding mass of 
the rock sample with different saturations $(30 \%, 50 \%, 70 \%$, $90 \%$, and $100 \%$ ) was obtained according to

$$
m_{t}=m_{\mathrm{d}}(1-\omega)+\omega m_{\mathrm{s}}
$$

where $m_{t}$ is the corresponding weight of the rock sample in different saturated states, $m_{\mathrm{d}}$ is the weight of the dry rock sample, $\omega$ represents the saturation of the rock samples, and $m_{\mathrm{s}}$ is the weight of the saturated rock sample. After obtaining the required saturation, the rock sample is sealed using plastic wrap and then packed in a plastic bag and sealed in water to keep the rock-sample saturation constant. Figure 1(e) shows the water sealing device for the rock samples.

2.2.2. Freeze-Thaw Cycle Test. Before the freeze-thaw cycle, the rock samples with different saturated states were placed in the water sealing device for a week to achieve a uniform distribution of water in the rock samples. The freeze-thaw cycle is carried out using a water-sealed device to keep the saturation stable. The rock sample is frozen for 12 hours at $-20^{\circ} \mathrm{C}$ and thawed for 12 hours at $20^{\circ} \mathrm{C}$. A freeze-thaw cycle takes place every 24 hours. The number of freeze-thaw cycles is set to 30, the approximate number of days in a month. The equipment for the freeze-thaw test is shown in Figure 1(d).

2.2.3. Nuclear Magnetic Resonance Test. After the freezethaw cycles, the first set of rock samples were vacuum saturated for 24 hours, and then, the nuclear magnetic resonance test was conducted. The nuclear magnetic resonance test equipment is shown in Figure 1(g). We used an NMR instrument (MacroMR12-150H-I, Suzhou Niumag Analytical Instrument Corporation, Suzhou, China) with a magnetic field strength of $0.3 \pm 0.05 \mathrm{~T}, \mathrm{H}$ proton resonance frequency of $12.77 \mathrm{MHz}$, and coil radio frequency pulse frequency of $1.499 \mathrm{MHz}$.

2.2.4. Creep Test. The conventional uniaxial compression test was performed on the second set of rock samples with different saturated states to obtain the stress level of creep. The loading is controlled by the deformation, with a loading rate of $0.002 \mathrm{~mm} / \mathrm{s}$, and the peak strength of rock samples with different saturation was obtained. The third group of rock samples determined the graded loading stress levels according to $30 \%, 40 \%, 50 \%, 60 \%, 70 \%, 80 \%$, and $90 \%$ of the second group's peak strength. Each level was loaded for $24 \mathrm{~h}$, and the loading rate was $0.02 \mathrm{MPa} / \mathrm{s}$. The surrounding area of the rock samples was smeared with petroleum jelly and wrapped in a thin plastic rubber sleeve before loading to ensure the stability of the internal saturation during the loading process.

The test loading device uses the TAW-1000 rock mechanics testing machine, which can perform conventional uniaxial and triaxial compression and creep tests. The testing machine consisted of four main units: conventional triaxial, servo loading, deformation monitoring, and data acquisition units. The maximum axial stress can reach $1000 \mathrm{KN}$. The maximum confining stress can reach $100 \mathrm{MPa}$. The loading device is shown in Figure 1(f).

\section{Results}

\subsection{Nuclear Magnetic Resonance Test after Freeze- Thaw Cycle}

3.1.1. $T_{2}$ Spectrum Distribution Analysis. The rock sample mainly comprises a mineral skeleton and pores. In a fully saturated state, NMR can be used to detect the signal strength of water in each pore and the total porosity, which in turn can determine the nuclear magnetic resonance characteristics. The particle and surface characteristics of the rock samples are reflected by the specific surface area. The lateral relaxation time $\mathrm{T}_{2}$ of the rock samples is determined by the fluid volume and the specific surface area in the rock pores [12]. Therefore, the $\mathrm{T}_{2}$ spectrum can clearly and intuitively quantify the internal pore structure of the rock sample.

Figure 2 shows the distribution of the $\mathrm{T}_{2}$ spectrum for rock samples with different saturated states after freezethaw cycles. The figure declares that, after the freeze-thaw cycles, the pore distribution of the rock samples presents a three-peak distribution and two peaks are the main representative forms. The variation trends of the $\mathrm{T}_{2}$ spectrum distribution curves are very similar. They all gradually move to the upper-right corner as the saturation increases. Based on the principle that the relaxation time $T_{2}$ is positively correlated with the pore size, combined with the position where the $\mathrm{T}_{2}$ spectrum distribution peak appears, different relaxation time intervals can be attributed to different pore types, namely, $\left(r<0.1 \mu \mathrm{m}, \mathrm{T}_{2}<7 \mathrm{~ms}\right)$ micropores, $(0.1<r<1 \mu \mathrm{m}$, $\left.7<\mathrm{T}_{2}<700 \mathrm{~ms}\right)$ mesopores, and $\left(r>1 \mu \mathrm{m}, \mathrm{T}_{2}>700 \mathrm{~ms}\right)$ macropores [22]. From the lateral relaxation time $\mathrm{T}_{2}$, we can see that the pore-distribution characteristics change significantly as the saturation reaches $90 \%$. After freezing and thawing, mesopores replace the small pores to a significant extent and become the main pore form, indicating that after the saturation reaches $70 \%$, the rock sample freeze-thaw damage is mainly reflected in the development of micropores, which causes an increase in mesopores.

3.1.2. $\mathrm{T}_{2}$ Spectrum Area and Porosity Analysis. The $\mathrm{T}_{2}$ spectrum area of NMR can reflect the changes in the size and number of pores in the rock, and the peak area is positively correlated with the corresponding pore size and number [23]. The $\mathrm{T}_{2}$ spectrum area is used to quantify the law governing the changes in the internal structure of rock samples with different saturations under freezing and thawing conditions, facilitating the evaluation of the degree of rock damage. Table 3 shows the total area of the $T_{2}$ spectrum and the areas of micropores, mesopores, and macropores under different saturation conditions after the freeze-thaw cycle. It is clearly observed that the total area of the $\mathrm{T}_{2}$ spectrum gradually increases with increases in saturation.

During the freeze-thaw cycle of the rock samples, there is mutual conversion among the three types of pores. The degree of increase in the volume of each type of pore is not the same. The percentage of differing pore volumes in the total pore volume of the rock samples changes at different saturation levels. The proportion of the total area of the $\mathrm{T}_{2}$ 


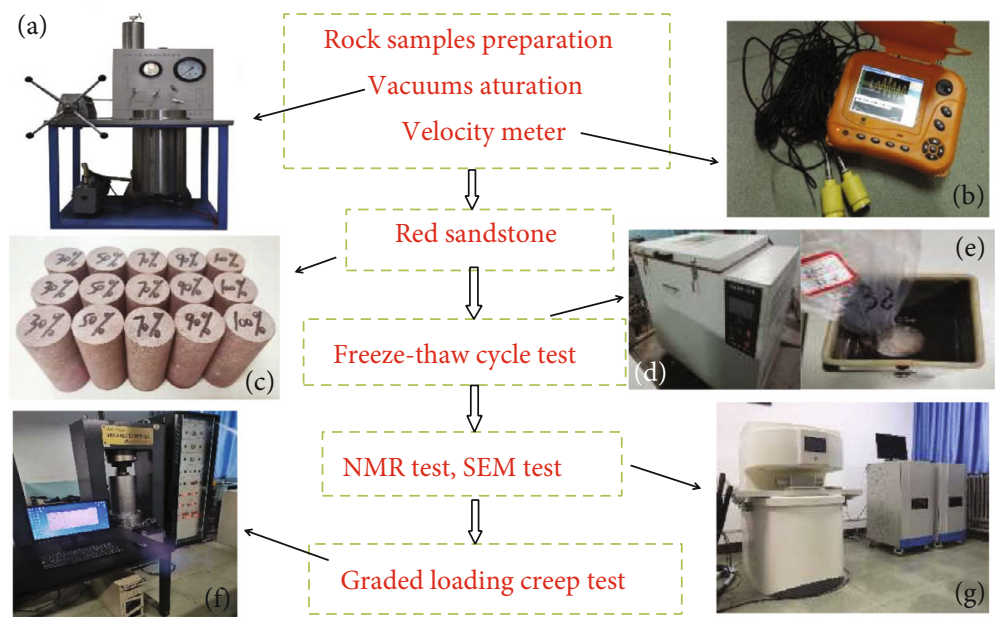

FIGURE 1: Flow chart of the experimental procedure.

TABLE 2: Average values of physical parameters for rock samples.

\begin{tabular}{lcccc}
\hline P-wave velocity $(\mathrm{m} / \mathrm{s})$ & Dry density $\left(\mathrm{g} / \mathrm{cm}^{3}\right)$ & Porosity $(\%)$ & Saturated water content $(\%)$ & Saturated density $\left(\mathrm{g} / \mathrm{cm}^{3}\right)$ \\
\hline 1863 & 2.31 & 9.56 & 5.29 & 2.45 \\
\hline
\end{tabular}

spectrum is shown in Figure 3. It can be seen from the figure that the inside of the rock sample is mainly composed of micropores and mesopores after freeze-thaw cycles, which account for about $50 \%$ of the total pore volume-the ratio of macropores to the total volume of pores is below $2 \%$. The damage of the rock samples caused by the freeze-thaw cycles is mainly in the form of micropores and mesopores. With increases in saturation, the percentage of mesopore area gradually increases, and when the saturation reaches $90 \%$, the peak area of mesopores gradually becomes the main peak. It shows that, when the saturation increases from $70 \%$ to $90 \%$, the internal frost-heave force of the rock sample increases continuously, and the critical value of freeze-thaw damage is reached [11].

3.1.3. Porosity Changes with Saturation. Porosity is the most commonly used and most important index for evaluating the characteristics of pores in porous materials. In this study, the change in the porosity of the rock sample after the freeze-thaw cycles was calculated using Equation (2) via the saturation method [24]:

$$
\Phi=\frac{m_{\mathrm{s}}-m_{\mathrm{d}}}{\rho_{\mathrm{w}} V_{\mathrm{b}}}
$$

where $\Phi$ is the porosity of the rock sample, $m_{\mathrm{s}}$ is the weight of the saturated sample, $m_{\mathrm{d}}$ is the weight of the dry rock sample, $\rho_{\mathrm{w}}$ is the density of saturating water, and $V_{\mathrm{b}}$ is the bulk volume of the rock sample.

Figure 4 shows the change curve for porosity and the $\mathrm{T}_{2}$ spectrum area of rock samples with respect to saturation after freeze-thaw cycles. The porosity of the rock sample exhibits a nonlinear growth trend with increases in saturation, indicating that the internal volume of the rock sample increases with an increase in the number of freeze-thaw cycles. When the saturation increases from $30 \%$ to $70 \%$, the porosity only increases by $13.66 \%$, the total area of the $\mathrm{T}_{2}$ spectrum increases by $17.92 \%$, and the rock sample damage is low. When the saturation changes from $70 \%$ to $100 \%$, the porosity increased by $23.60 \%$, the total area of the $\mathrm{T}_{2}$ spectrum increased by $28.79 \%$, and critical freeze-thaw damage occurred. Therefore, it is obvious that the pores grow slowly in the first stage and rapidly in the second. The damage inside the rock sample is smallest in the first stage; therefore, the porosity and total area of the $\mathrm{T}_{2}$ spectrum increase slowly. The increase in porosity is mainly due to the soluble minerals and cement in the rock sample gradually dissolving with the increase in saturation, weakening the connections between particles. This makes the pore volume increase continuously, and the damage caused by frost heave is small. However, the effective freeze-thaw damage occurs in the second stage. As the saturation increases, the frost-heave force increases and the internal fissures of the rock sample expand. The continuous dissolution of soluble minerals and cement by water molecules aggravates the destruction of the rock structure. The pore size inside the rock sample changes significantly, resulting in an increase in the porosity and the total area of the $\mathrm{T}_{2}$ spectrum [10]. From the above analysis, it can be concluded that the change in the internal microstructure of the rock sample by freeze-thaw cycles is greatly affected by the saturation level.

3.2. Scanning Electron Microscope Analysis. To further analyze the microstructural characteristics of the rock sample affected by saturation, slices were taken from the same position inside the rock sample after the freeze-thaw cycle, and the scanning electron microscopy test under 100x magnification was performed. The scanning result is shown in Figure 5. The PCAS software binarizes the information of the scanning electron microscope [25], and the black portion of the binarized image represents the pores and cracks of the 


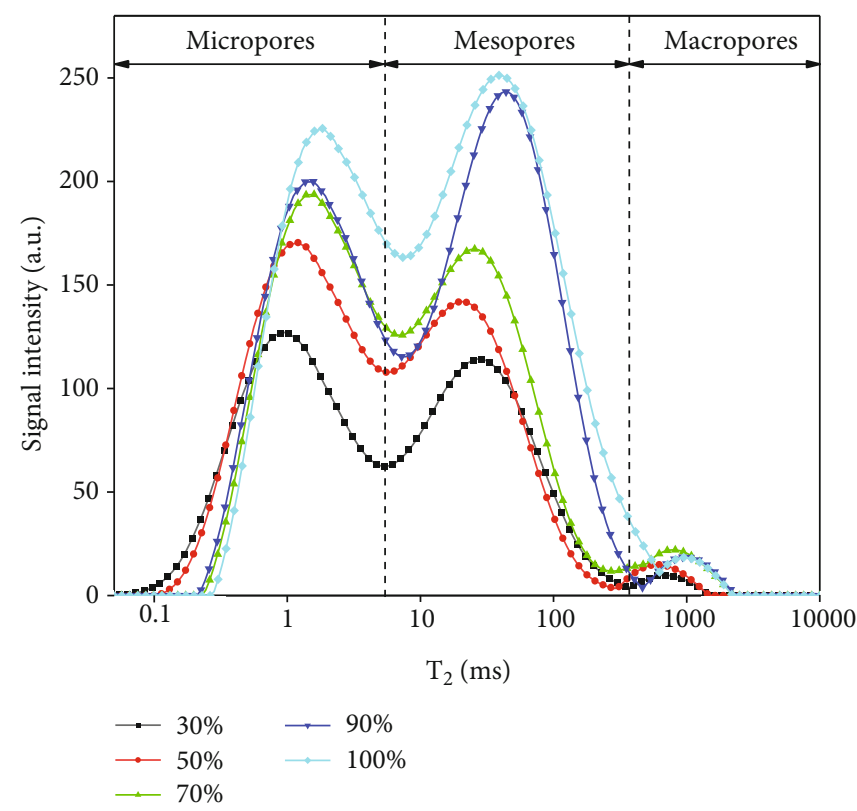

FIgURE 2: $T_{2}$ spectrum distribution of rock samples with different saturated states.

TABLE 3: NMR results of rock samples under different saturated states.

\begin{tabular}{lcccc}
\hline $\begin{array}{l}\text { Saturation } \\
\omega\end{array}$ & $\begin{array}{c}\text { Total } \\
\text { area }\end{array}$ & $\begin{array}{c}\text { Micropore } \\
\text { area }\end{array}$ & $\begin{array}{c}\text { Mesopore } \\
\text { area }\end{array}$ & $\begin{array}{c}\text { Macropore } \\
\text { area }\end{array}$ \\
\hline $30 \%$ & 11659 & 6021 & 5457 & 181 \\
$50 \%$ & 12640 & 6831 & 5543 & 229 \\
$70 \%$ & 13748 & 7100 & 6435 & 213 \\
$90 \%$ & 15528 & 6868 & 8370 & 290 \\
$100 \%$ & 15706 & 6550 & 8847 & 309 \\
\hline
\end{tabular}

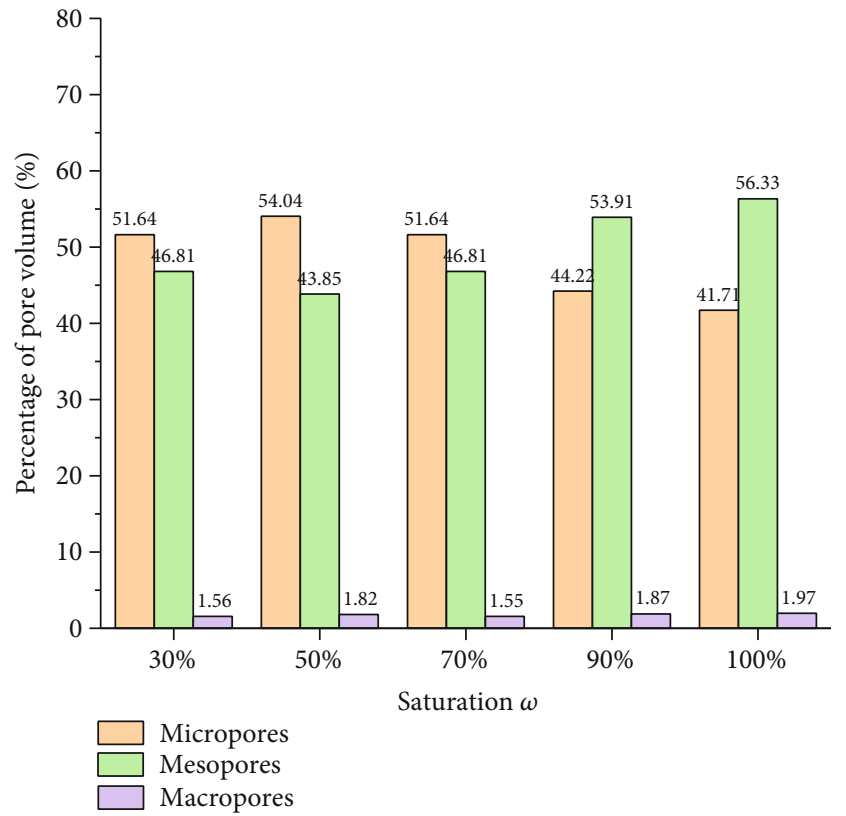

Figure 3: Proportional of three pore types in the total area of $\mathrm{T}_{2}$ spectrum.

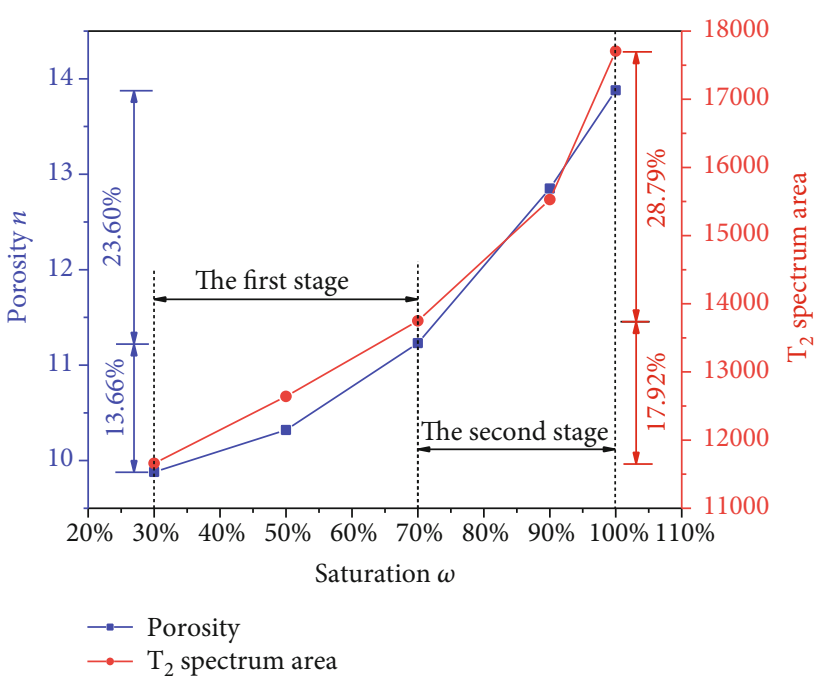

FIgURE 4: Porosity and $\mathrm{T}_{2}$ spectrum area change curve with saturation.

scanned slice. From the binarization image, it is clearly observed that as the saturation gradually increases, the number of pores inside the rock sample increases and significant cracks develop. Under low-saturation conditions, owing to the small frost-heave force on the rock sample, even after 30 freeze-thaw cycles, the mineral particles of the rock sample are still tightly bonded, the grain boundary is not obvious, and the pores are fewer. As the saturation increases, particularly when it reaches $90 \%$, the frost-heave force gradually increases, the bonding state of the cement and mineral particles in the rock sample gradually change, and the dissolution of the cement gradually accelerates. As a result, there is a significant loss of cement between particles, weakening their connection. Further, the dissolution holes increase in 


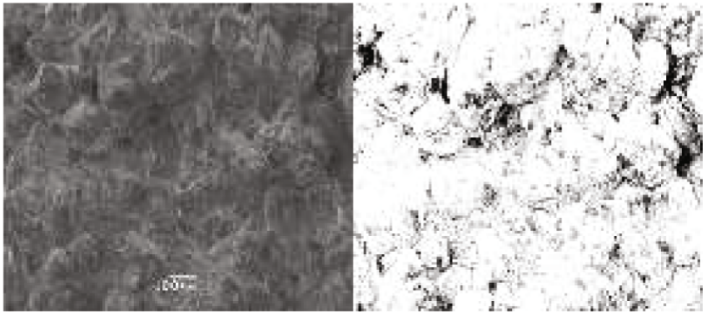

(a) $30 \%$

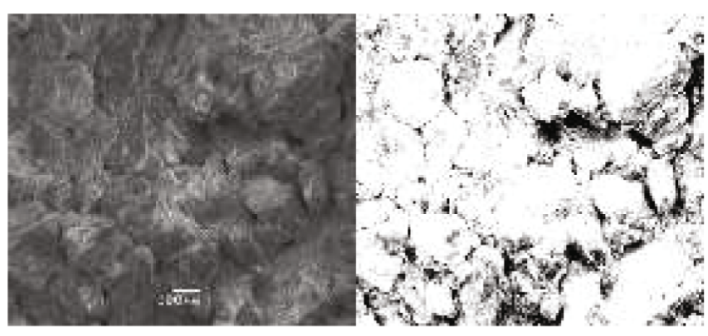

(c) $70 \%$

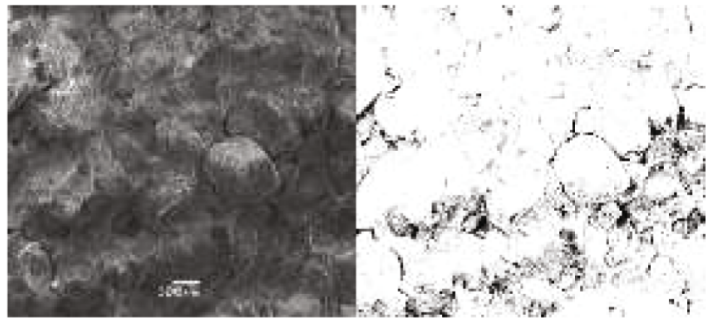

(b) $50 \%$

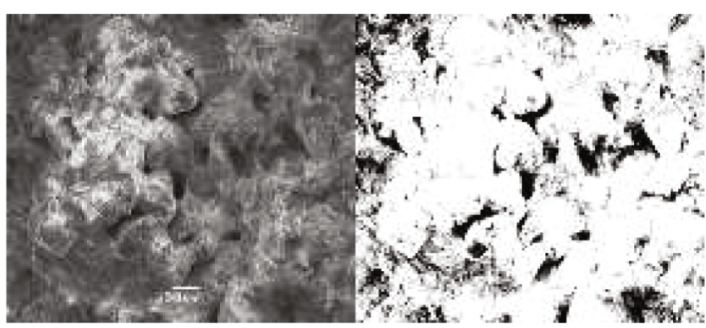

(d) $90 \%$

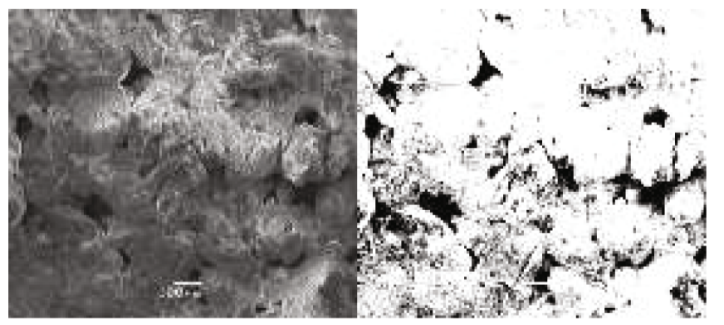

(e) $100 \%$

FIGURE 5: Scanning electron microscopy and binarization images of rock samples with different saturations.

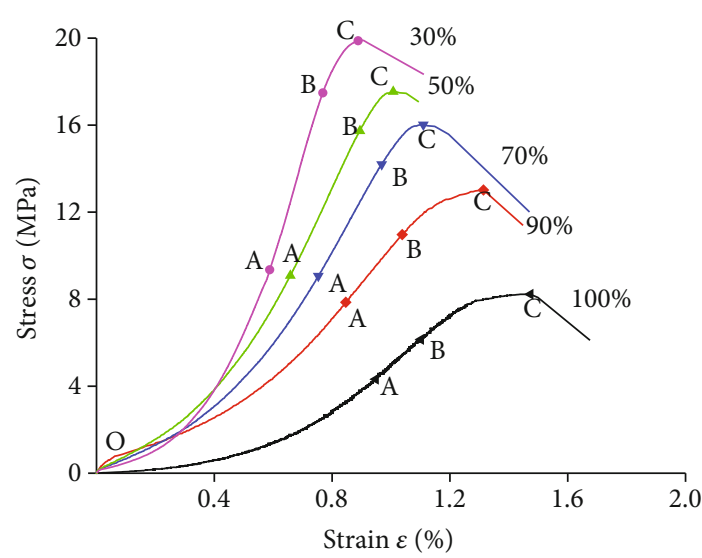

FIGURE 6: Stress-strain curves of differently saturated rock samples.

number and penetration cracks through particles appear. The above analysis demonstrates that, when the saturation reaches $70 \%$, freeze-thaw cycle damage gradually appears, a value that can be used as the critical saturation for freezethaw damage.

3.3. Uniaxial Strength Test Analysis. To determine the loading classification, uniaxial compression tests on rock samples with different saturation states were carried out. The stressstrain curve is shown in Figure 6, and the test results are shown in Table 4 . In the curve, $\mathrm{OA}$ is the compaction stage,
TABle 4: Mechanical parameters of rock samples with different saturations.

\begin{tabular}{lccccc}
\hline \multirow{2}{*}{ Parameter } & \multicolumn{5}{c}{ Saturation $\omega$} \\
& $30 \%$ & $50 \%$ & $70 \%$ & $90 \%$ & $100 \%$ \\
\hline Uniaxial strength $\sigma_{\mathrm{f}}(\mathrm{MPa})$ & 17.19 & 14.50 & 10.51 & 7.87 & 5.12 \\
Elastic modulus $E(\mathrm{GPa})$ & 2.13 & 1.94 & 1.52 & 1.09 & 0.57 \\
\hline
\end{tabular}

$\mathrm{AB}$ is the linear-elastic stage of pore and crack development, and $\mathrm{BC}$ is the plastic development stage [26]. The table shows that the strength and elastic modulus both decrease with increases in saturation. When the saturation increases from $30 \%$ to $70 \%$, the decrease in strength and elastic modulus is smaller, decreasing by $38.86 \%$ and $28.64 \%$, respectively; when the saturation is increased from $70 \%$ to $100 \%$, it decreases by $51.29 \%$ and $62.5 \%$, respectively, which represents a much larger decline than the former case. This shows that, under the action of freeze-thaw cycles, the instantaneous mechanical properties of rock samples are greatly affected by saturation, and the critical value of instantaneous mechanical damage occurs when the saturation increases from $70 \%$ to $90 \%$.

\subsection{Analysis of Creep Test Results}

3.4.1. Influence of Saturation on Creep Deformation in Rock Samples. Figure 7 shows the uniaxial creep curves of rock 


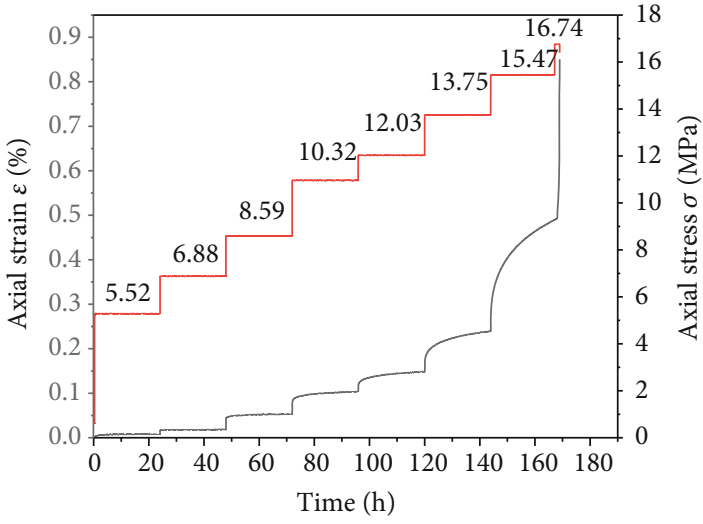

(a) $30 \%$

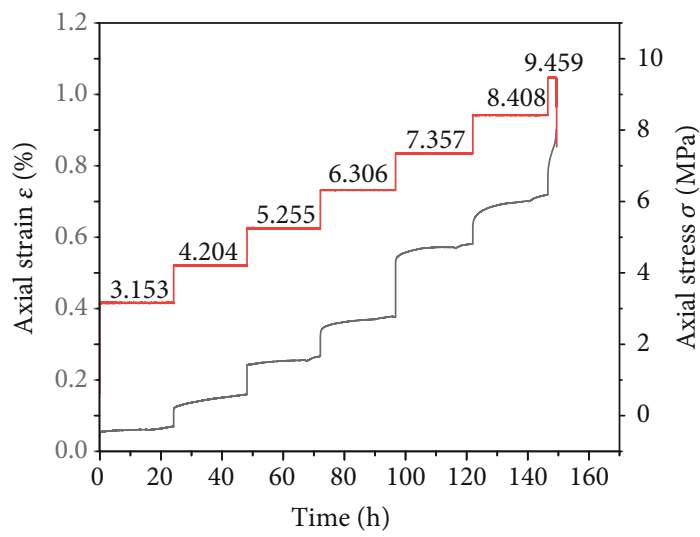

(c) $70 \%$

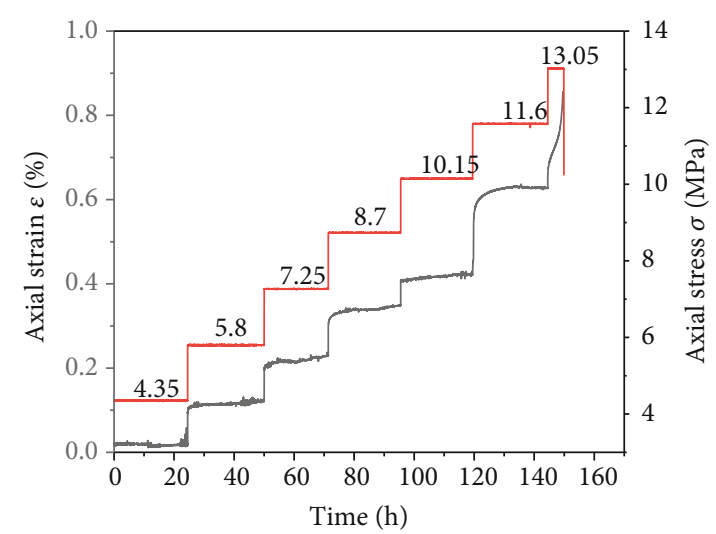

(b) $50 \%$

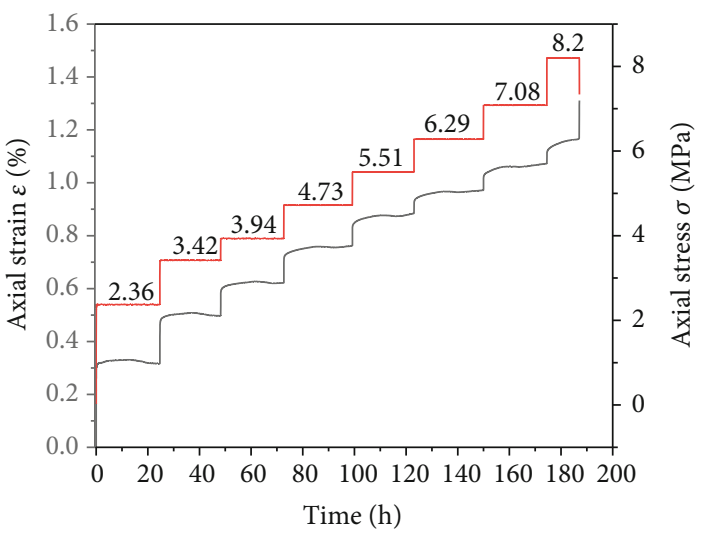

(d) $90 \%$

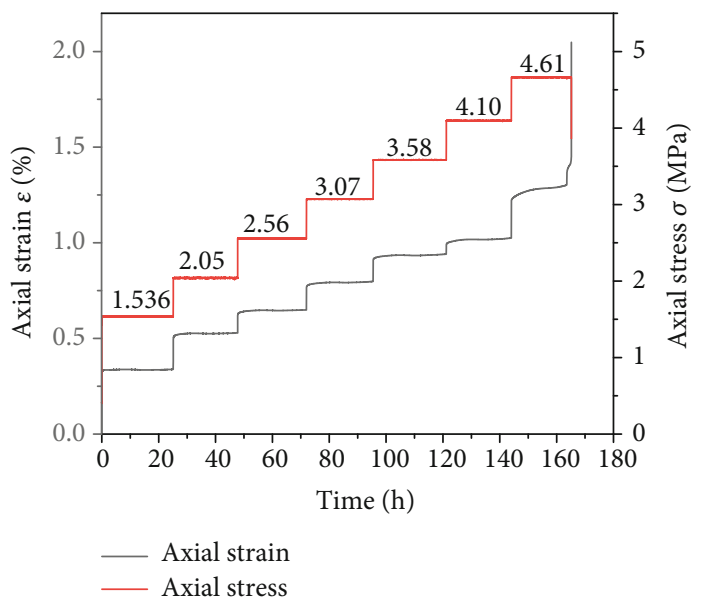

(e) $100 \%$

Figure 7: Creep curves of rock samples with different states of saturation.

TABle 5: Axial creep strain of rock sample under graded loading.

\begin{tabular}{lccccccc}
\hline \multirow{2}{*}{ Saturation $\omega$} & & \multicolumn{3}{c}{ Axial creep strain of different graded loading stress levels $\varepsilon / 10^{-2}$} & & \\
& $30 \%$ & $40 \%$ & $50 \%$ & $60 \%$ & 0.1486 & 0.2394 & 0.4951 \\
\hline $30 \%$ & 0.0083 & 0.0175 & 0.0531 & 0.1035 & 0.3485 & 0.4251 & 0.6264 \\
$50 \%$ & 0.0185 & 0.1225 & 0.2294 & 0.3485 & 0.8572 \\
$70 \%$ & 0.0693 & 0.1594 & 0.2631 & 0.3745 & 0.5853 & 0.7165 \\
$90 \%$ & 0.3138 & 0.4926 & 0.6217 & 0.7624 & 0.8843 & 0.9717 \\
$100 \%$ & 0.3375 & 0.5216 & 0.6465 & 0.7975 & 0.9441 & 1.0171 \\
\hline
\end{tabular}




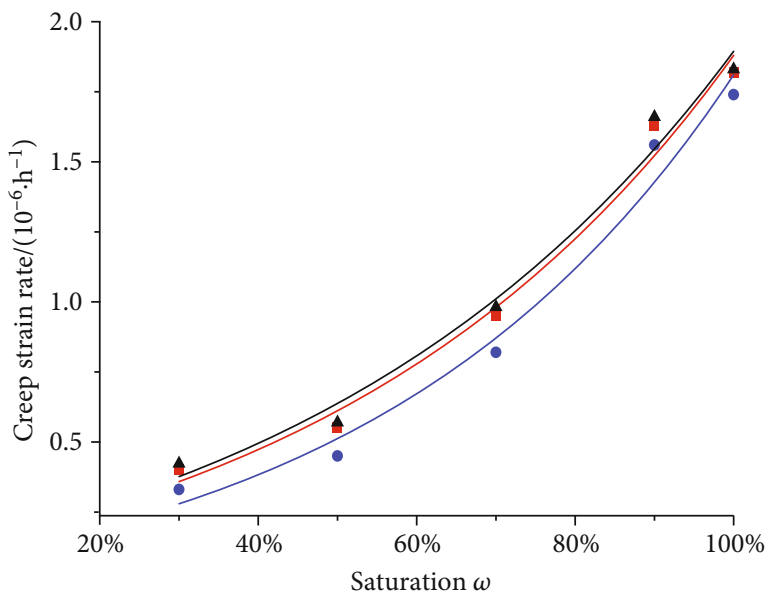

$80 \% \sigma_{\mathrm{c}}: \Delta$ Creep strain rate _ Curve fitting

$60 \% \sigma_{\mathrm{c}}$ : - Creep strain rate Curve fitting

$40 \% \sigma_{\mathrm{c}}$ : - Creep strain rate — Curve fitting

FIGURE 8: Steady-state creep rate under different loading stress levels.

samples with different saturated states after freeze-thaw cycles. The figure is visible that the rock sample immediately produces instantaneous strain under the action of axial stress, which gradually increases with increases in saturation. Under the action of long-term stress, the creep characteristics of rock samples are relatively obvious. As the stress increases, the creep deformation increases significantly, and the characteristics of decelerated creep and stable creep appear [27]. Under the action of the final load, the characteristics of accelerated creep appear, and the creep rate and creep deformation gradually increase with increases in creep time, until failure. As the saturation increases, the creep deformation gradually increases under the load of the same level, and the creep curve gradually becomes steeper. Looking at Table 5, under the first level of horizontal load, relative to the previous saturation level, the axial creep strain increment of the rock samples with $50 \%, 70 \%, 90 \%$, and $100 \%$ saturation are $0.0102,0.0508,0.2445$, and 0.0237 , respectively; under the second level of horizontal load, the additional values are $0.105,0.0369,0.3332$, and 0.029 , respectively. From the above analysis, it can be concluded that, under the load of the same level, the axial creep strain of the rock sample gradually increases with the increase of saturation. This is because the internal damage of the rock sample is greatly affected by saturation under the action of a freeze-thaw cycle. According to the analysis in sections, when the saturation reaches $70 \%$, the internal particle cementation of the rock sample weakens, and the number of pores increases, leading to a reduction in creep mechanical properties.

3.5. Influence of Saturation on the Creep Rate of Rock Samples. Figure 8 shows the steady-state creep rates of rock samples with different saturated states at $40 \%, 60 \%$, and $80 \%$ loading stress levels. This is evident from the fitting curve that, under the same stress level, the steady-state creep rate of the rock sample increases nonlinearly with increases in saturation. Taking the $60 \%$ stress loading level as an example, when the saturation is low, the steady-state creep rate of the rock sample increases only slightly. When the saturation is $30 \%$, the steady-state creep rate of the rock sample is $4.204 \times 10^{-7}$, and when the saturation is $50 \%$, it is 5.562 $\times 10^{-7}$, exhibiting an increase of $32.31 \%$. As the saturation continues to increase, the increase in the steady-state creep rate of the rock sample gradually increases. When the saturation is $70 \%$, the steady-state creep rate is $9.571 \times 10^{-7}$; when it reaches $90 \%$, the steady-state creep rate is $1.634 \times$ $10^{-6}$, which is an increase of $70.73 \%$. The same change pattern is also shown at the $40 \%$ and $80 \%$ loading stress level. It can be concluded that saturation has a great influence on the steady-state creep rate of the rock samples. As the saturation increases, the steady-state creep rate of the rock sample increases gradually. This could be because of the difference in the degree of damage caused by the freeze-thaw cycle to the rock samples in different saturated states. When the saturation reaches $70 \%$, owing to the increase in internal water molecules, the frost-heaving force increases, causing internal pores and microcracks in the rock-sample structure to develop and expand, resulting in increased damage and the gradual deterioration of mechanical properties.

Under the final stage of loading, the rock samples with different saturated states underwent creep failure. The change of the curves of axial strain and creep strain rate under the final stress level with time is shown in Figure 9. To visually analyze the curve characteristics of the accelerated creep stage of a $100 \%$ saturation rock sample, only the portion of the curve after the axial-strain change is shown in the figure.

Under the action of freezing and thawing, the rock samples with different saturated states experienced the decelerated-creep stage, the stable-creep stage, and the accelerated-creep stage, and rapid destruction occurs in the accelerated creep stage; the creep-failure law is different under the action of the final level of stress. Further, 90\% and $100 \%$ rock samples have a shorter accelerated creep stage, because when they reach a higher saturation, freezing and thawing cause their plasticity to decrease; as shown in the figure, the creep rate curve is approximately barrelshaped-it first gradually decreases, then remains stable, and finally increases suddenly. The results of a comparison among the creep failure stress level, creep duration, and creep rate of rock samples in different saturated states under the action of freezing and thawing are shown in Table 6 . The rock samples with a saturation of $30 \%, 50 \%, 70 \%, 90 \%$, and $100 \%$ fail at stresses of $15.47 \mathrm{MPa}, 13.05 \mathrm{MPa}, 9.46 \mathrm{MPa}$, 8.2 $\mathrm{MPa}$, and 4.61 MPa, respectively; at low levels of saturation, the creep time gradually decreases with increases in saturation. When the saturation is greater than $70 \%$, the creep time gradually increases; the creep rate of the rock sample increases with increases in saturation.

3.6. Creep Failure Morphology. Table 7 shows the creep failure morphology and sketch map of rock samples with different saturated states after freeze-thaw cycles. It is clear that the failure mode of the rock sample is shear failure. When 


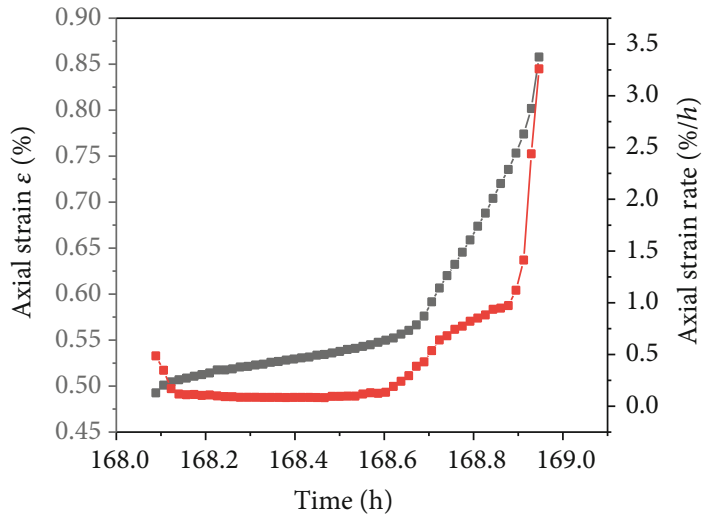

(a) $30 \%$

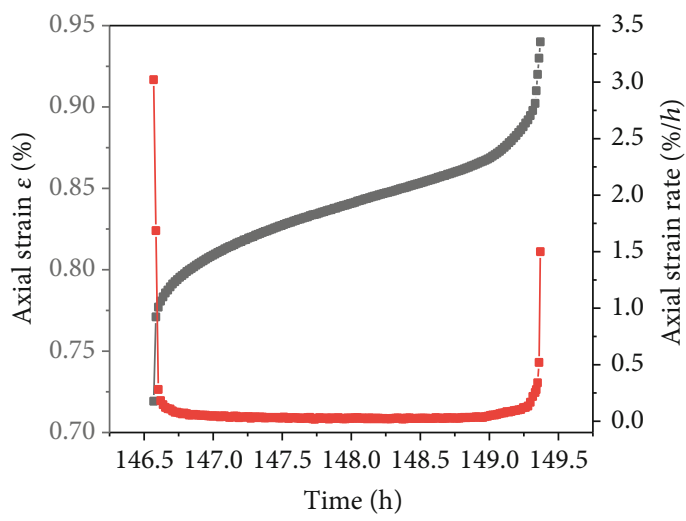

(c) $70 \%$

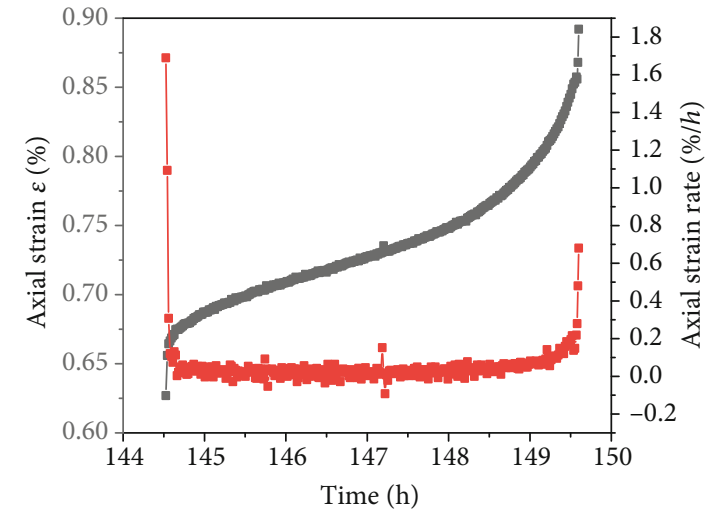

(b) $50 \%$

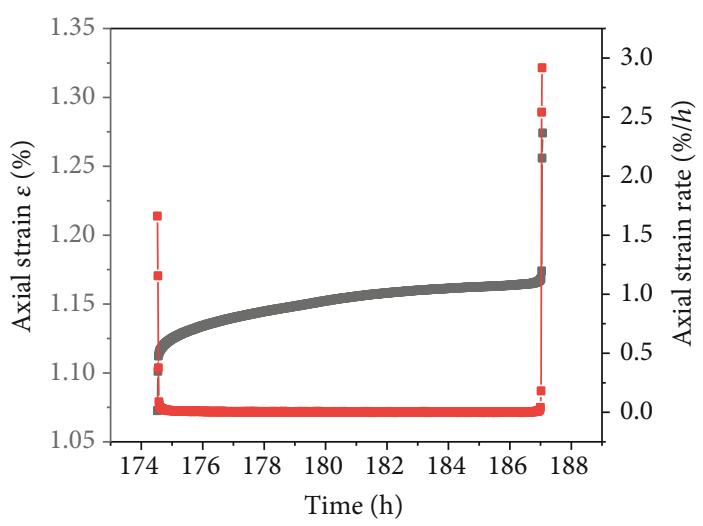

(d) $90 \%$

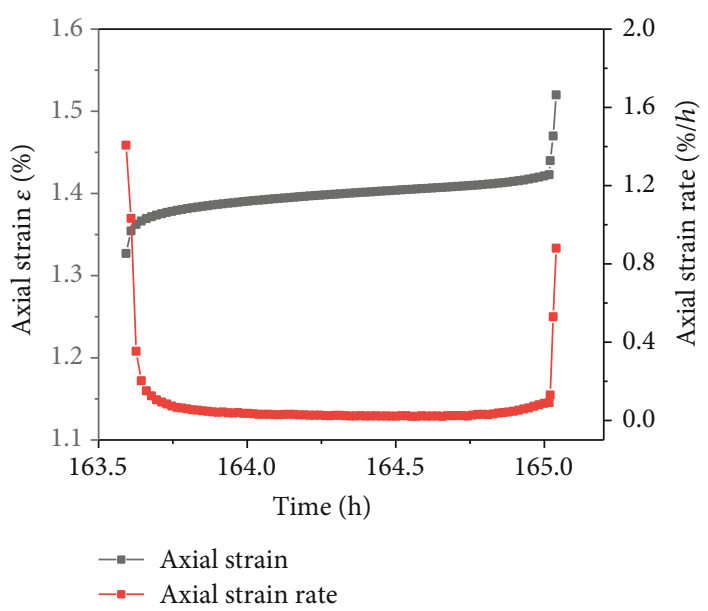

(e) $100 \%$

FIGURE 9: Change of creep rate of rock sample under failure stress.

the saturation is $30 \%$, only one primary crack appears. As the saturation increases, the failure cracks of the rock sample gradually increase, and microcracks appear. The crack spacing of the rock sample gradually forms, and tension characteristics manifest. This is because, as the saturation increases, the freeze-thaw cycle causes the cementation between the particles of the rock sample to weaken, increasing cracks. The internal cracks in the rock sample structure gradually develop and expand under long-term loading, eventually evolving into multicrack shear failure [28].

\section{Creep Model with Different Saturated States under Freeze-Thaw Cycles}

4.1. Establishing the Creep Model. From the above experimental analysis, it can be concluded that rock samples with different saturated states, under the action of freezing and thawing, sequentially experience the decelerated-creep stage, the stable-creep stage, and the accelerated-creep stage. Further, the creep properties of the rock sample are related to the saturation, stress state, and loading time. The classic 
TABLE 6: Creep parameters of specimens under failure stress.

\begin{tabular}{lccccc}
\hline Saturation $\omega$ & Failure stress $\sigma(\mathrm{MPa})$ & Creep time $(\mathrm{h})$ & $\begin{array}{c}\text { Decelerated creep stage } \\
\text { Initial creep rate }\end{array}$ & $\begin{array}{c}\text { Stable creep stage } \\
\text { Steady-state creep rate }\end{array}$ & $\begin{array}{c}\text { Accelerated creep stage } \\
\text { Accelerated creep rate }\end{array}$ \\
\hline $30 \%$ & 16.74 & 0.96 & $2.829 \times 10^{-6}$ & $6.328 \times 10^{-7}$ & $1.726 \times 10^{-6}$ \\
$50 \%$ & 13.05 & 5.33 & $3.357 \times 10^{-6}$ & $7.389 \times 10^{-7}$ & $2.185 \times 10^{-6}$ \\
$70 \%$ & 9.46 & 2.73 & $1.583 \times 10^{-6}$ & $7.842 \times 10^{-7}$ & $2.603 \times 10^{-6}$ \\
$90 \%$ & 8.20 & 12.74 & $3.824 \times 10^{-6}$ & $8.617 \times 10^{-7}$ & $3.015 \times 10^{-6}$ \\
$100 \%$ & 4.61 & 25.59 & $0.426 \times 10^{-5}$ & $0.103 \times 10^{-6}$ & $0.413 \times 10^{-5}$ \\
\hline
\end{tabular}

TABLE 7: Creep failure morphology of rock samples.

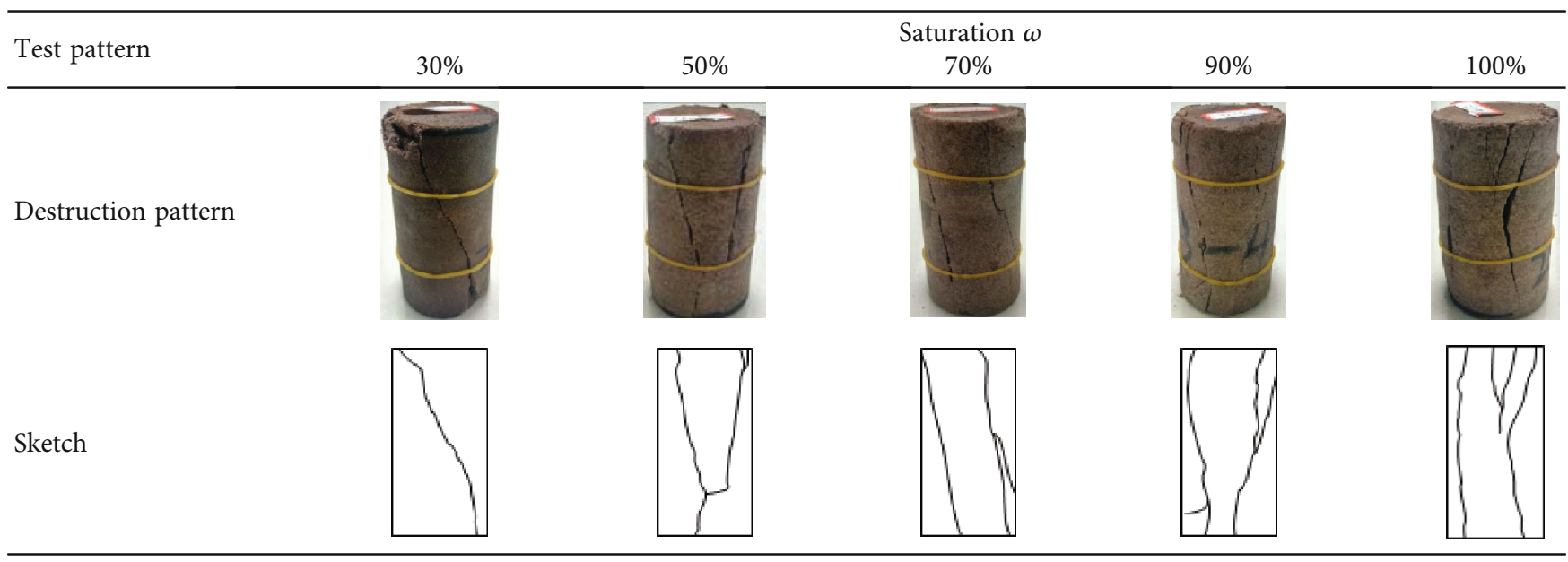

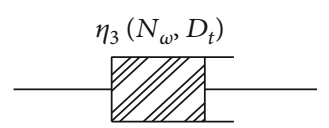

Figure 10: Freeze-thaw damage to viscous components.

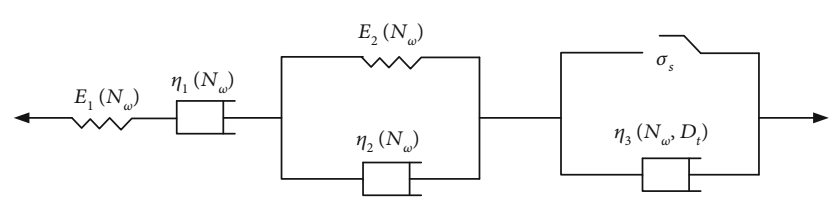

Figure 11: Creep model.

Burgers model can fully reflect the decelerated-creep and stable-creep stage during the creep test, but it cannot describe the accelerated-creep stage. Therefore, in this paper, a modified viscous-plastic body is connected in series on the basis of the Burgers model. By introducing the damage variable to consider the accumulation of damage in the creep process, describing the variation of the viscosity coefficient with the creep process and accounting for the effect of saturation on the viscosity coefficient, a freeze-thaw-damage viscous element was constructed. The viscous components are shown in Figure 10.

The freeze-thaw-damage viscous element is a Newtonian body, and its constitutive relationship is shown in

$$
\sigma=\eta_{3}\left(N_{\omega}, D_{t}\right) \dot{\varepsilon}
$$

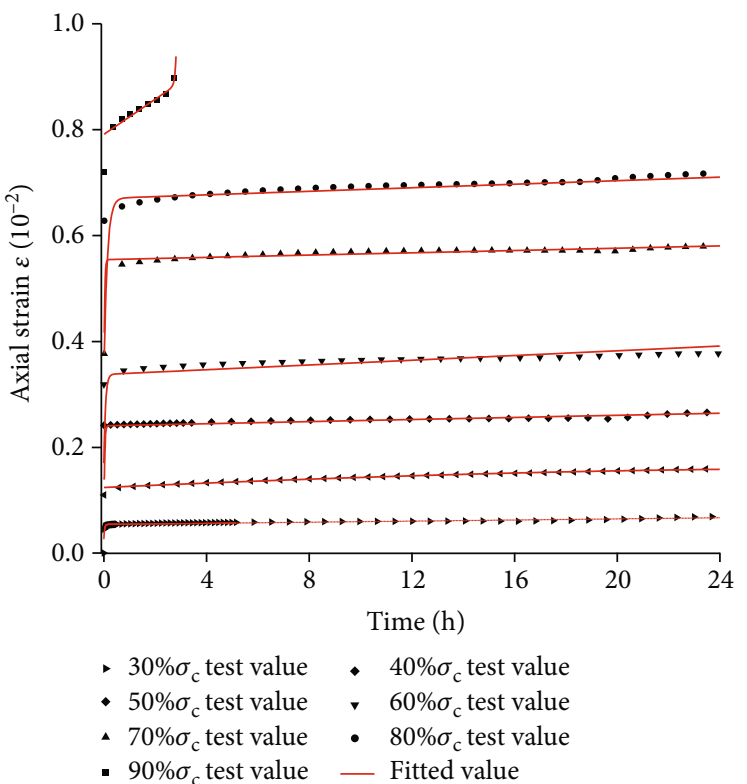

Figure 12: Creep verification curve of $70 \%$ saturation rock samples.

where $\sigma$ is the stress of the viscous element, $\dot{\varepsilon}$ is the strain rate, and $\eta_{3}\left(N_{\omega}, D_{t}\right)$ is the viscosity coefficient of the freeze-thaw-damage viscous element. 
TABLE 8: Creep model parameters of $70 \%$ saturation rock samples.

\begin{tabular}{|c|c|c|c|c|c|c|c|c|}
\hline Saturation $\omega$ & Stress $(\mathrm{MPa})$ & $E_{1}$ & $E_{2}$ & $\eta_{1}$ & $\eta_{2}$ & $\alpha$ & $\eta_{3}$ & $R^{2}$ \\
\hline \multirow{7}{*}{$70 \%$} & 3.153 & 0.384 & 0.624 & 46.326 & 13.68 & - & - & 0.95 \\
\hline & 4.204 & 0.396 & 0.673 & 46.175 & 16.33 & - & - & 0.99 \\
\hline & 5.255 & 0.382 & 0.531 & 46.158 & 15.37 & _ & _- & 0.94 \\
\hline & 6.306 & 0.631 & 0.522 & 46.033 & 12.35 & _- & - & 0.93 \\
\hline & 7.357 & 0.543 & 0.501 & 44.384 & 17.95 & _- & - & 0.94 \\
\hline & 8.408 & 0.412 & 0.413 & 40.569 & 19.32 & - & - & 0.96 \\
\hline & 9.459 & 0.596 & 0.338 & 33.218 & 26.31 & 0.037 & 8.236 & 0.99 \\
\hline
\end{tabular}

Considering the influence of saturation and long-term loading on the viscosity coefficient, the coefficient of the viscous element is shown in

$$
\eta_{3}\left(N_{\omega}, D_{t}\right)=\eta_{3}\left(N_{\omega}\right)\left(1-D_{t}\right)
$$

where $\eta_{3}\left(N_{\omega}\right)$ is the viscosity coefficient after a certain number of freeze-thaw cycles and $D_{t}$ is the damage variable $\left(0 \leq D_{t}<1\right)$.

A significant amount of research has shown that the damage caused by long-term loading in the process of rock creep has a negative exponential function relationship with time [29], as shown in

$$
D_{t}=1-e^{-\alpha t}
$$

where $\alpha$ is the coefficient related to the material properties and saturation of the rock sample and $t$ is time.

Therefore, considering the joint influence of saturation and long-term load, the viscosity coefficient is

$$
\eta_{3}\left(N_{\omega}, D_{t}\right)=\eta_{3}\left(N_{\omega}\right) e^{-\alpha\left(N_{\omega}\right) t}
$$

where $\alpha\left(N_{\omega}\right)$ is the material coefficient of the rock sample at a certain number of freeze-thaw cycles at a degree of saturation.

Therefore, the constitutive relationship of the viscous element is

$$
\varepsilon=\frac{\sigma}{\alpha\left(N_{\omega}\right) \eta_{3}\left(N_{\omega}\right)}\left[e^{\alpha\left(N_{\omega}\right) t}-1\right] .
$$

The model is composed of four parts connected in series: a water-containing elastic element, a water-containing viscous element, a water-containing viscoelastic element, and a water-containing viscous-plastic body. The creep model is shown in Figure 11 , where $E_{1}, E_{2}, \eta_{1}$, and $\eta_{2}$ are parameters related to saturation; $\eta_{3}$ is the parameter related to loading time and saturation. The creep equation is obtained as shown in Equations (8) and (9):

when $\sigma \leq \sigma_{s}$,

$$
\varepsilon=\frac{\sigma}{E_{1}\left(N_{\omega}\right)}+\frac{\sigma}{\eta_{1}\left(N_{\omega}\right)} t+\frac{\sigma}{E_{2}\left(N_{\omega}\right)}\left(1-e^{\left(E_{2}\left(N_{\omega}\right) / \eta_{2}\left(N_{\omega}\right)\right) t}\right)
$$

when $\sigma \geq \sigma_{s}$,

$$
\begin{aligned}
\varepsilon= & \frac{\sigma}{E_{1}\left(N_{\omega}\right)}+\frac{\sigma}{\eta_{1}\left(N_{\omega}\right)} t+\frac{\sigma}{E_{2}\left(N_{\omega}\right)}\left(1-e^{\left(E_{2}\left(N_{\omega}\right) / \eta_{2}\left(N_{\omega}\right)\right) t}\right) \\
& +\frac{\sigma-\sigma_{s}}{\alpha\left(N_{\omega}\right) \eta_{3}\left(N_{\omega}\right)}\left[e^{\alpha\left(N_{\omega}\right) t}-1\right] .
\end{aligned}
$$

4.1.1. Model Validation. The Boltzmann superposition principle is used to transform the creep curve under the staged-loading condition into the creep curve under the separate-loading condition. The 1stOpt mathematical optimization analysis software is used to identify the model parameters. The calculated results of the established freezethaw-damage creep model are in good agreement with the test results and can simultaneously describe instantaneous deformation, decelerated creep, stable creep, and accelerated creep processes. Owing to space limitations, only the creep verification curve and creep-parameter evolution results of the $70 \%$ saturation rock sample is listed, as shown in Figure 12 and Table 8.

\section{Conclusions}

The freeze-thaw cycle has a significant influence on the longterm mechanical properties of rocks. However, most current creep research is only carried out in the fully saturated state. This paper conducts NMR, scanning electron microscopy, and uniaxial compression creep tests on red sandstone in different states of saturation after freeze-thaw cycles. The main results of this research are summarized as follows.

Under the action of freeze-thaw cycles, as the saturation of rock samples increases, the $\mathrm{T}_{2}$ spectrum distribution shifts to the right, the total area of the $\mathrm{T}_{2}$ spectrum gradually increases, and the porosity increases. Further, when the saturation increased from $70 \%$ to $90 \%$, the distribution characteristics of pores changed significantly. After freeze-thaw cycles, mesopores replaced micropores, becoming the main pore form.

By SEM image, it can be seen that the number of pores in the rock samples gradually increases with increasing saturation levels. When the saturation reaches $70 \%$, freeze-thaw cycle damage gradually appears, the number of dissolution holes increases, and penetration fracture occurs in the particle. 
Under uniaxial compression, rock samples in different saturated states experience the compaction stage, linearelastic stage, and plastic stage. The instantaneous mechanical properties of rock samples are greatly affected by saturation. The critical value appears when the saturation increases from $70 \%$ to $90 \%$.

Under long-term loading, saturation has a significant influence on the time-efficiency characteristics of the rock sample during the freeze-thaw cycle. With increases in saturation, the creep deformation gradually increases. When it reaches $70 \%$, the axial creep strain increases greatly, the creep rate increases, the creep failure stress decreases, and the creep time under the final level of stress increases significantly. This shows that the saturation level of $70 \%$ is the critical saturation for the deterioration of the mechanical properties of the rock sample.

A modified viscous-plastic body is connected in series on the basis of the Burgers model. The damage accumulation and saturation change in the creep process are fully considered. The freeze-thaw-damage viscous element-with the viscosity coefficient $\eta_{3}\left(N_{\omega}, D_{t}\right)$-is introduced, and creep parameters were fitted using the experimental data. The numerical-calculation values of the model are in good agreement with the experimental values. The creep model established can accurately reflect the staged-loading creep state of rock samples in different saturated states under the action of freezing and thawing. The model can provide a theoretical basis for investigating the time-efficiency characteristics of rocks in different water-saturation states.

\section{Data Availability}

The data used to support the findings of this study are included within the article, displayed by figures and tables.

\section{Conflicts of Interest}

The authors declare no conflict of interest.

\section{Acknowledgments}

This research was supported by the National Natural Science Foundation of China (Nos. 11972283, 11872299, and 41702346) and the Natural Science Foundation of Shaanxi Province, China (No. 2017JM1039), which are greatly appreciated.

\section{References}

[1] J. L. Li, L. Y. Zhu, K. P. Zhou, S. P. Cao, and H. W. Liu, "Experimental investigation on the effects of ambient freeze-thaw cycling on creep mechanical properties of sandstone under step loading," IEEE Access, vol. 7, pp. 108513-108520, 2019.

[2] Z. J. Zhou, H. C. Zhan, J. Y. Hu, and C. N. Ren, "Characteristics of unloading creep of tuffaceous sandstone in East Tianshan Tunnel under freeze-thaw cycles," Advances in Materials Science and Engineering, vol. 2019, Article ID 7547564, 16 pages, 2019.

[3] G. Q. Chen, F. Guo, J. C. Wang, and Y. X. Zhou, "Experimental study on triaxial creep characteristics of quartz sandstone after freezing and thawing," Rock and Soil Mechanics, vol. 38, no. s1, pp. 203-210, 2017.

[4] X. R. Yang, J. N. Jiang, S. Y. Wang, and F. R. Zhang, "Experimental study on the creep characteristics of gneiss under freeze-thaw cycles," Rock and Soil Mechanics, vol. 40, no. 11, pp. 4331-4340, 2019.

[5] X. X. Liu, S. N. Li, Z. P. Xu, Y. Li, and Y. M. Zhou, "Research on the creep model of carbonaceous shale under freeze-thaw cycles," China Journal of Highway and Transport, vol. 32, no. 11, pp. 137-145, 2019.

[6] F. R. Zhang, J. N. Jiang, X. R. Yang, and F. Y. Shen, "Test and model study of granite shear creep under freeze-thaw cycles," Rock and Soil Mechanics, vol. 41, no. 2, pp. 509-519, 2020.

[7] Y. Niu, X. P. Zhou, J. Z. Zhang, and Q. H. Qian, "Experimental study on crack coalescence behavior of double unparallel fissure- contained sandstone specimens subjected to freezethaw cycles under uniaxial compression," Cold Regions Science and Technology, vol. 158, pp. 166-181, 2019.

[8] X. P. Zhou, Y. Niu, J. Z. Zhang, X. C. Shen, Y. Zheng, and F. Berto, "Experimental study on effects of freeze-thaw fatigue damage on the cracking behaviors of sandstone containing two unparallel fissures," Fatigue \& Fracture of Engineering Materials \& Structures, vol. 42, no. 6, pp. 1322-1340, 2019.

[9] J. P. McGreevy and W. B. Whalley, "Rock moisture content and frost weathering under natural and experimental conditions: a comparative discussion," Arctic Antarctic and Alpine Research, vol. 17, no. 3, pp. 337-346, 1985.

[10] Q. S. Liu, S. B. Huang, Y. S. Kang, and X. Z. Cui, "Research progress and thinking on freeze-thaw damage of fractured rock masses," Chinese Journal of Rock Mechanics and Engineering, vol. 34, no. 3, pp. 452-471, 2015.

[11] A. Prick, "Critical degree of saturation as a threshold moisture level in frost weathering of limestones," Permafrost and Periglacial Processes, vol. 8, no. 1, pp. 91-99, 1997.

[12] A. Prick, "Dilatometrical behaviour of porous calcareous rock samples subjected to freeze-thaw cycles," Catena, vol. 25, no. 1-4, pp. 7-20, 1995.

[13] T. C. Chen, M. R. Yeung, and N. Mori, "Effect of water saturation on deterioration of welded tuff due to freeze-thaw action," Cold Regions Science and Technology, vol. 38, no. 2-3, pp. 127136, 2004.

[14] A. Al-Omari, K. Beck, X. Brunetaud, Á. Török, and M. AlMukhtar, "Critical degree of saturation: a control factor of freeze-thaw damage of porous limestones at Castle of Chambord, France," Engineering Geology, vol. 185, pp. 7180, 2015.

[15] P. Zhang, Y. Zou, X. Wang, T. Jiang, H. Lin, and P. Cao, “An elasto-visco-plastic model based on stress functions for deformation and damage of water-saturated rocks during the freeze-thaw process," Construction and Building Materials, vol. 250, article 118862, 2020.

[16] X. R. Yang, J. N. Jiang, and Z. B. Jiang, "Study on creep test and damage model of soft rock under water content," Rock and Soil Mechanics, vol. 39, pp. 167-174, 2018.

[17] X. J. Liu, X. R. Liu, T. X. Wang, and J. B. Wang, "Study on creep constitutive model of shallow metamorphic slate considering water-bearing degradation effect," Chinese Journal of Rock Mechanics and Engineering, vol. 33, no. 12, pp. 2384-2389, 2014.

[18] J. Z. Zhang, X. P. Zhou, and P. Yin, "Visco-plastic deformation analysis of rock tunnels based on fractional derivatives," 
Tunnelling and Underground Space Technology, vol. 85, pp. 209-219, 2019.

[19] J. B. Wang, Q. Zhang, Z. P. Song, and Y. W. Zhang, "Experimental study on creep properties of salt rock under longperiod cyclic loading," International Journal of Fatigue, vol. 143, p. 106009, 2021.

[20] J. B. Wang, Q. Zhang, Z. P. Song, and Y. W. Zhang, "Creep properties and damage constitutive model of salt rock under uniaxial compression," International Journal of Damage Mechanics, vol. 29, no. 6, pp. 902-922, 2020.

[21] X. D. Luo, N. Jiang, X. Y. Fan, N. F. Mei, and H. Luo, "Effects of freeze-thaw on the determination and application of parameters of slope rock mass in cold regions," Cold Regions Science and Technology, vol. 110, pp. 32-37, 2015.

[22] J. L. Li, R. B. Kaunda, and K. P. Zhou, "Experimental investigations on the effects of ambient freeze-thaw cycling on dynamic properties and rock pore structure deterioration of sandstone," Cold Regions Science and Technology, vol. 154, pp. 133-141, 2018.

[23] Y. J. Shen, Y. Z. Wang, X. Wei, H. L. Jia, and R. X. Yan, "Investigation on meso-debonding process of the sandstoneconcrete interface induced by freeze-thaw cycles using NMR technology," Construction and Building Materlals, vol. 252, p. 118962, 2020.

[24] L. M. Anovitz and D. R. Cole, "Characterization and analysis of porosity and pore structures," Reviews in Mineralogy and Geochemistry, vol. 80, no. 1, pp. 61-164, 2015.

[25] B. Liu, J. Z. Shi, J. Zhou, and C. Tang, "Quantification and characterization of microporosity by image processing, geometric measurement and statistical methods: application on SEM images of clay materials," Applied Clay Science, vol. 54, no. 1, pp. 97-106, 2011.

[26] H. M. Zhang and G. S. Yang, "Experimental study on damage and mechanical properties of freeze-thawed rock," Journal of China Coal Society, vol. 38, no. 10, pp. 1756-1762, 2013.

[27] X. R. Yang, A. N. Jiang, and M. X. Li, "Experimental investigation of the time-dependent behavior of quartz sandstone and quartzite under the combined effects of chemical erosion and freeze-thaw cycles," Cold Regions Science and Technology, vol. 161, pp. 51-62, 2019.

[28] Y. S. Kang, C. C. Hou, B. Liu, Q. S. Liu, H. M. Sang, and Y. C. Tian, "Frost deformation and a quasi-elastic-plastic-creep constitutive model for isotropic freezing rock," International Journal of Geomechanics, vol. 20, no. 8, article 04020119, 2020.

[29] F. B. Chen, Q. J. Zuo, Y. Y. Wu, Z. J. Zhang, and X. Q. Zhao, "Study on the macro-fine-micro mechanism of slate expansion process in rich water environment," Chinese Journal of Rock Mechanics and Engineering, vol. 39, no. 1, pp. 126-137, 2020. 